\title{
Labeling of Anti-SAS1B with Zirconium-89 as a Novel Immune-PET Probe for Uterine Cancer Imaging
}

\author{
Nouri Elmekharam*, Sundaresan Gobalakrishnan, \\ Celina Thadigiri, Li Wang, Ali Gawi, Jamal Zweit \\ Center for Molecular Imaging, Department of Radiology, Department of Chemistry, Virginia Commonwealth University, \\ Richmond, VA, USA \\ Email: *nouri.elmekharam@vcuhealth.org
}

How to cite this paper: Elmekharam, N., Gobalakrishnan, S., Thadigiri, C., Wang, L., Gawi, A. and Zweit, J. (2021) Labeling of Anti-SAS1B with Zirconium-89 as a Novel Immune-PET Probe for Uterine Cancer Imaging. Journal of Biosciences and Medicines, 9, 30-41.

https://doi.org/10.4236/jbm.2021.911004

Received: October 4, 2021

Accepted: November 7, 2021

Published: November 10, 2021

Copyright $\odot 2021$ by author(s) and Scientific Research Publishing Inc. This work is licensed under the Creative Commons Attribution International License (CC BY 4.0).

http://creativecommons.org/licenses/by/4.0/ (c) (i) Open Access

\begin{abstract}
Overexpression of Sperm Acrosomal SLLP1 Binding protein (SAS1B) in various cancer types, including uterine cancer cells, was discovered a few years ago, and different monoclonal antibodies (anti-SAS1B) that specifically bind to SAS1B antigens were developed. Labeling of these antibodies with radionuclides can provide an opportunity for imaging and radioimmunotherapy. The objective of this study was to label anti-SAS1B (SB5) with Zirconium-89 $\left({ }^{89} \mathrm{Zr}\right)$ for PET imaging and determine its biodistribution. Anti-SAS1B (SB5) antibody was labeled with ${ }^{89} \mathrm{Zr}$ indirectly using the chelator desferrioxamine $\mathrm{B}$ (DFO), which is currently a best linker for ${ }^{89} \mathrm{Zr}$. The antibody, SB5, was first conjugated to DFO with a ratio of $1: 5$ and then labeled with $250 \mu \mathrm{Ci}$ of ${ }^{89} \mathrm{Zr}$. Results of PET imaging in mouse-bearing uterine cancer tumor showed a limited uptake. The bio-distribution study matched the PET imaging and confirmed the uptake by the tumor, and the accumulation in bones. In conclusion, labeling of anti-SAS1B could provide an effective way of uterine cancer detection and treatment progression.
\end{abstract}

\section{Keywords}

SAS1B, Radio-Labeling, Zirconium-89, Uterine Cancer

\section{Introduction}

Molecular imaging has had a transformative impact on academic research, industry, and the clinical field [1]. Molecular imaging can also provide quantitative information, which is important in monitoring cancer progression over time or treatment response [2]. The positron emission tomography (PET) is one of the 
molecular imaging modalities that has provided non-invasive and quantitative physiological data relating to disease pathophysiology, receptor expression, enzyme activity, and cellular metabolism [3] [4]. PET imaging depends on radionuclide decay by positron emission [5]. Radionuclides are chemically attached to molecular ligands designed to trace biochemical phenomena in vivo, such as the expression of surface antigen on cancer cells [6] [7]. Uterine cancers are considered aggressive cancers [8] and frequently have a terminal prognosis because of the lack of early diagnosis and effective treatment options [9]. According to American Cancer Society statistics, the estimation of new uterine cancer cases for 2020 was about 66,000 , and the deaths related to uterine cancer were about 13,000 [10]. During the last decade, overexpression of SAS1B protein on the cell surface in many types of tumors, including uterine tumor, was discovered by Dr. John C, Herr and coworkers, who also developed different monoclonal antibodies (anti-SAS1B) against this protein and demonstrated specific binding to SAS1B [11]. Because of their sensitivity and specificity and biological half-live Monoclonal antibodies have been used for more than two decades to target cancer cells [12] [13]. Furthermore, for their potential treatment, antibodies have been loaded with radioisotopes to serve as a vehicle taking them specifically to their target [14] [15]. This advantageously prevents the systemic effects of radiation on the normal organs [5]. In addition, based on the radionuclide's properties, labeled antibodies with some radionuclides can also provide imaging capability, which is useful for cancer diagnosis and treatment monitoring [16]. Early diagnosis and treatment assessment is crucial for cancer therapy [17].

Pharmacokinetics studies have shown that intact antibodies typically have a half-life of about 3 - 4 days [18]. Therefore, this requires the use of radionuclides with long-hour's half-lives. Among PET imaging radionuclides, ${ }^{89} \mathrm{Zr}$ is attractive, because it has been safely used in the clinic for many years, and it has several advantages, including a long half-life of 78.4 hours, which matches the biological half-lives of the antibodies [19] [20]. In addition, ${ }^{89} \mathrm{Zr}$ decays low average positron energy of $395 \mathrm{keV}$, which provides high-resolution PET images. Based on these properties [21], ${ }^{89} \mathrm{Zr}$ was selected as radio nuclei to label SB5 antibody for generating a novel tracer (probe) to obtain quality images, and its tumor uptake.

\section{Material and Methods}

[ ${ }^{89} \mathrm{Zr}$ ]-Oxalate was produced in-house at VCU hospital on a PET-Trace Cyclotron (Sofie Biosciences, Richmond, VA, USA) using the ${ }^{89} \mathrm{Y}(\mathrm{p}, \mathrm{n}){ }^{89} \mathrm{Zr}$ reaction. The DFO chelator was purchased from Macrocyclics. Uterine cancer cell lines SNU539 and Anti-SAS1B antibodies were provided by late Dr. John C, Herr at UVA. Female nude mice, 3 weeks old, were obtained from the National Cancer Institute in Bethesda.

\section{Cell Culture}

SNU539 (Seoul National University) uterine cancer cell lines were grown in Roswell Park Memorial Institute 1640 (RPMI-1640) medium (Gibco-BRL, 
Grand Island, NY, USA). The medium was supplemented with $10 \%$ fetal calf serum (Hyclone Laboratories, Logan, UT, USA), 1\% L-glutamine, and 1 penicillin/streptomycin (Gibco-BRL). The cells were incubated at $37 \mathrm{oC}$ in a $5 \% \mathrm{CO} 2$ incubator for routine cell culturing.

\subsection{Conjugation of Anti-SAS1B (SB5) with DFO}

AntiSAS1B and Zirconium-89 were linked using DFO, because it is the most prominent chelator of $\mathrm{Zr}^{4+}$. The DFO is a hexadentate siderophore containing three hydroxamate groups for chelating metals such as ${ }^{89} \mathrm{Zr}$ and a primary amine tail for conjugation to antibodies. Several principle preclinical studies have been conducted using DFO to label antibodies with ${ }^{89} \mathrm{Zr}$; however, this labelling caused accumulation of free ${ }^{89} \mathrm{Zr}$ [22]. To resolve this issue, many studies have attempted to improve the linkage between DFO and the antibody [23], while others concentrated on improving the chelator itself [24]. During preliminary experiments a 1:5 molar ratio SB5 to DFO was found optimal for the reaction and these ratios was used for conjugating SB5 with DFO in $500 \mu$ of phosphate-buffered saline solution (PBS), and the $\mathrm{pH}$ was adjusted to $8.8-9.0$ using $0.1 \mathrm{M}$ sodium bicarbonate. The mixture was incubated at $37^{\circ} \mathrm{C}$ and at a rotating speed of $300 \mathrm{rpm}$ for 60 minutes.

\subsection{SB5-DF0 Characterization}

The conjugation yield of SB5-DFO was monitored using HPLC (High-performance liquid chromatography with ultraviolet detector) with a size exclusion column (SEC) (Superdex 200 10/300 column GE Healthcare, Piscataway, NJ USA) at room temperature. The mobile phase consisted of $0.01 \mathrm{M}$ phosphate buffer and $0.14 \mathrm{M} \mathrm{NaCl}, \mathrm{pH} 7.4$ at a flow rate of $0.5 \mathrm{~mL}$ min. UV detection was accomplished at $280 \mathrm{~nm}$ using a Waters $2489 \mathrm{UV}(10-\mathrm{mm}, 11-\mu \mathrm{L}$ analytical flow cell).

\subsection{Radiochemistry}

High-performance Liquid Chromatography Analysis: Zirconium-89 was received as $\left[{ }^{89} \mathrm{Zr}\right]$-oxalate. Therefore, conversion of $\left[{ }^{89} \mathrm{Zr}\right]$-oxalate to $\left[{ }^{89} \mathrm{Zr}\right]$-chloride using $1 \mathrm{M} \mathrm{HCl}$ was the first step before labeling anti-SAS1B (SB5). The reaction yield was monitored by HPLC. The HPLC was connected to a radio detector to detect the radioactivity signal of the labeled antibody. This is one of the methods used to determine the radiochemical purity of radiolabeled antibodies. The [ $\left.{ }^{89} \mathrm{Zr}\right]-$ DFO-SB5 solution (20 ul) was loaded on a HPLC using size exclusion column (SEC) (Superdex 200 10/300 column GE Healthcare, Piscataway, NJ USA). The mobile phase was $0.1 \mathrm{M}$ phosphate buffer and $0.14 \mathrm{M} \mathrm{NaCl}_{2}, \mathrm{pH} 7.4$, at a flow rate of $0.5 \mathrm{~mL}$ min. Radiochemical species were separated according to molecular size and weight, and the peak of the radiolabeled antibody was detected by matching the corresponding antibody peak (HPLC with UV detection)..

Thin-Layer Chromatography Analysis: The radiolabeled antibody $\left[{ }^{89} \mathrm{Zr}\right]-$ 
DFO-SB5 was also monitored by radio-TLC. Thin-layer chromatography was performed on TLC plates (silica gel plate, Sigma-Aldrich, St. Louis, MO). One ul of the final solution was spotted at the center of the $2 \mathrm{~cm}$ mark from the bottom of a $10 \mathrm{~cm}$ TLC plate. The spot was allowed to dry for 5 to 10 minutes. The plates were then placed into a TLC jar with $10 \%$ ammonium acetate and methanol (1:1) as a mobile phase. The plates were allowed to develop up to the $7 \mathrm{~cm}$ from the bottom (about 15 minutes). In this system, radiolabeled antibody remains at the origin, while free $\left[{ }^{89} \mathrm{Zr}\right]$ migrate to the solvent front.

Antibody Purification: The size exclusion column PD10 was used to further purify [ $\left.{ }^{89} \mathrm{Zr}\right]-\mathrm{DFO}-\mathrm{SB} 5$. This column allowed separating labeled antibodies from other radioactive components. The purification was then tested using TLC.

\section{Animals and tumor}

Animal experiments were performed according to the policies and guidelines of the Animal Care and Use Committee (IACUC) at Virginia Commonwealth University. About $(5 \times 106)$ of SNU539 cells mixed with $30 \%$ matrix gel were injected subcutaneously into the flanks of female nude mice ( 3 weeks old) to implant xenograft tumors. Tumor growth was monitored every other day. The tumor growth was slow as noticeable tumors were observed in approximately three weeks post tumor injection. The size of the tumor was measured three times during the week using a caliper. When the tumor size reached about $1 \mathrm{~cm}$ in diameter, mice were injected with $\left[{ }^{89} \mathrm{Zr}\right]$-labeled SB5 antibody.

\subsection{PET/CT Imaging}

The uptake of radiolabeled antibodies in tumor by the tumor-associated antigens and it's the distribution in other organs was quantitatively measured by [ ${ }^{89} \mathrm{Zr}$ ]-PET. A female nude mouse was injected via tail vein with $250 \mu \mathrm{Ci}$ of [ ${ }^{89} \mathrm{Zr}$ ]-DFO-SB5. After intervals of 2 hours, 24 hours, and 72 hours, the mice were anesthetized with $2 \%$ isoflurane inhalation anesthesia. The mice were positioned in PET/CT system, and images were obtained. The region-of-interest (ROI) was analyzed with the percent injected dose/gram of tissue (\%ID/g). The animal was imaged by both PET and CT. The CT images provided the anatomical background for the distribution of the radioactivity.

\section{Biodistribution}

The biodistribution of $\left[{ }^{89} \mathrm{Zr}\right]-\mathrm{DFO}-\mathrm{SB} 5$ in animals was determined in different organs after injection and animal sacrifice. Six nude mice bearing SNU539 tumor xenografts were divided into two groups for treatment with labeled-antibodies via tail vein injection. The first group of 3 mice was injected with a solution of $\left[{ }^{89} \mathrm{Zr}\right]-\mathrm{DFO}-\mathrm{SB} 5$. The other groups of 3 mice were injected with the non-specific labeled antibody $\left[{ }^{89} \mathrm{Zr}\right]-\mathrm{DFO}-3 \mathrm{~A} 4$ (as negative control). The mice were sacrificed, blood and tissues were collected from each animal and weighed, and radioactivity of ${ }^{89} \mathrm{Zr}$ in each sample was determined by gamma-counting on a Perkin Elmer Wallac Wizard 1470. The radioactivity percent of injected dose per gram \%ID/g of each organ was calculated. The organs were 
collected include blood, heart, lung, liver, gallbladder, spleen, kidney, tumor, femur, and muscle.

First, confirm that you have the correct template for your paper size. This template has been tailored for output on the custom paper size $(21 \mathrm{~cm} * 28.5$ $\mathrm{cm}$ ). High-Performance Liquid Chromatography (HPLC) results showed a high reaction yield of DFO-SB5 cold conjugation (Figure 1). The peak of conjugated-DFO-SB5 was at 24 minutes retention time. The small peak at retention time 37.12 represents free DFO. The area under the peak represents the conjugation yield of DFO to SB5. As the HPLC chromatograph showed, about $92 \%$ of DFO was conjugated to SB5.

\section{Results}

\subsection{Characterization of Conjugated Antibody-DFO-SB5}

First, confirm that you have the correct template for your paper size. This template has been tailored for output on the custom paper size $(21 \mathrm{~cm} * 28.5 \mathrm{~cm})$. High-Performance Liquid Chromatography (HPLC) results showed a high reaction yield of DFO-SB5 cold conjugation (Figure 1). The peak of conjugated-DFO-SB5 was at 24 minutes retention time. The small peak at retention time 37.12 represents free DFO. The area under the peak represents the conjugation yield of DFO to SB5. As the HPLC chromatograph showed, about $92 \%$ of DFO was conjugated to SB5.

\subsection{Characterization of $89 \mathrm{Zr}-\mathrm{DFO}-\mathrm{SB} 5$}

\subsubsection{Radio-HPLC Chromatography}

Radio-HPLC was used to determine the radiolabeling yield of SB5. The radioactive signal of ${ }^{89} \mathrm{Zr}$ was validated using peaks on a UV-HPLC (Figure 2). The

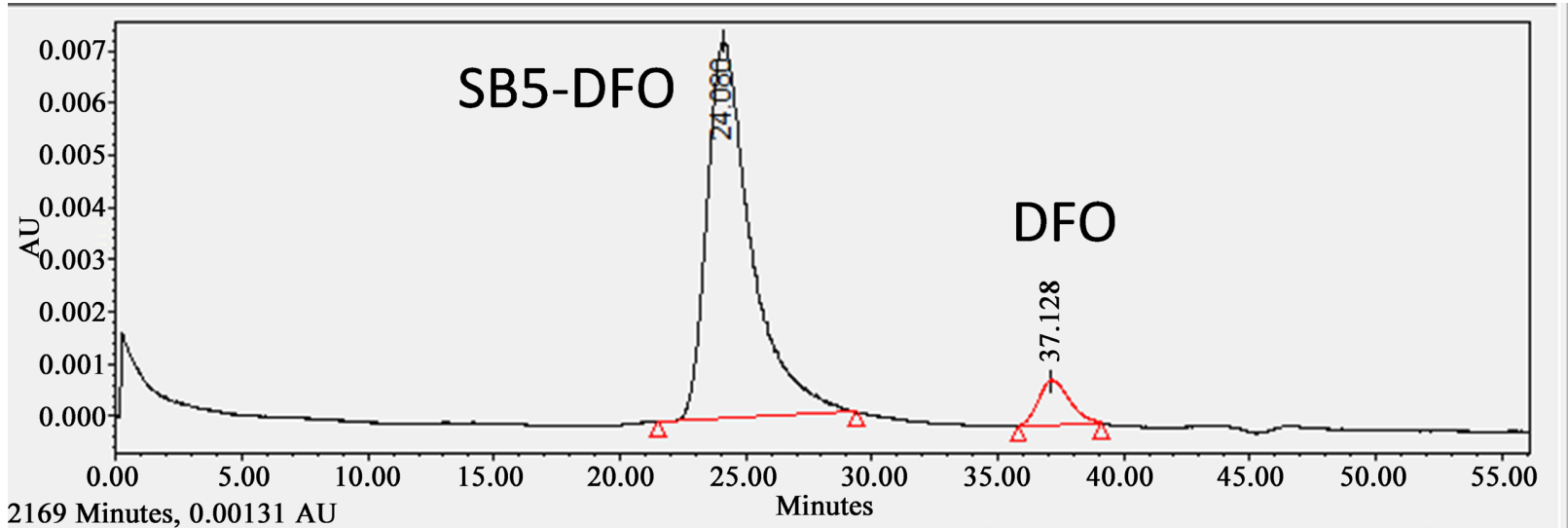

\begin{tabular}{|c|c|c|c|}
\hline $\begin{array}{c}\text { Retention Time } \\
(\mathrm{min})\end{array}$ & $\begin{array}{c}\text { Area } \\
\left(\mu \mathrm{V}^{2}\right)\end{array}$ & $\begin{array}{c}\text { Area } \\
(\%)\end{array}$ & $\begin{array}{c}\text { Height } \\
(\mu \mathrm{V})\end{array}$ \\
\hline 24.080 & 879,393 & 92.47 & 7214 \\
\hline 37.128 & 71,642 & 7.53 & 849 \\
\hline
\end{tabular}

Figure 1. Characterization of DFO-SBF conjugation reaction. Conjugation reaction (20 ul) was separated using an HPLC system as described in the text above. The chromatogram shows a $92 \%$ conjugation yield B5. 
radio-HPLC chromatograph showed that almost $70 \%$ of radioactive signal matched the UV signal of DFO-SB5. Few small peaks possibly represent the SB5 fragments.

\subsubsection{Thin-Layer Chromatography (Radio-TLC) of [ ${ }^{89} \mathrm{Zr}$-DFO-SB5]}

The radio-instant thin layer of chromatography showed a high radioactive signal of labeled SB5 with a very small signal representing free ${ }^{89} \mathrm{Zr}$ or $\left[{ }^{89} \mathrm{Zr}\right]-\mathrm{DFO}$. Almost $97 \%$ radioactivity was recovered with the DFO-SB5 conjugate (peak 1) and only a small fraction (3\%) of radioactivity was incorporated into SB5 fragments (peak2) (Figure 3).

\subsubsection{PET/CT Imaging}

The animal was imaged by both PET and CT. The CT image provided the anatomical background for the distribution of the radioactivity. As the image showed (Figure 4), the vast majority of radioactivity appeared to be clearing

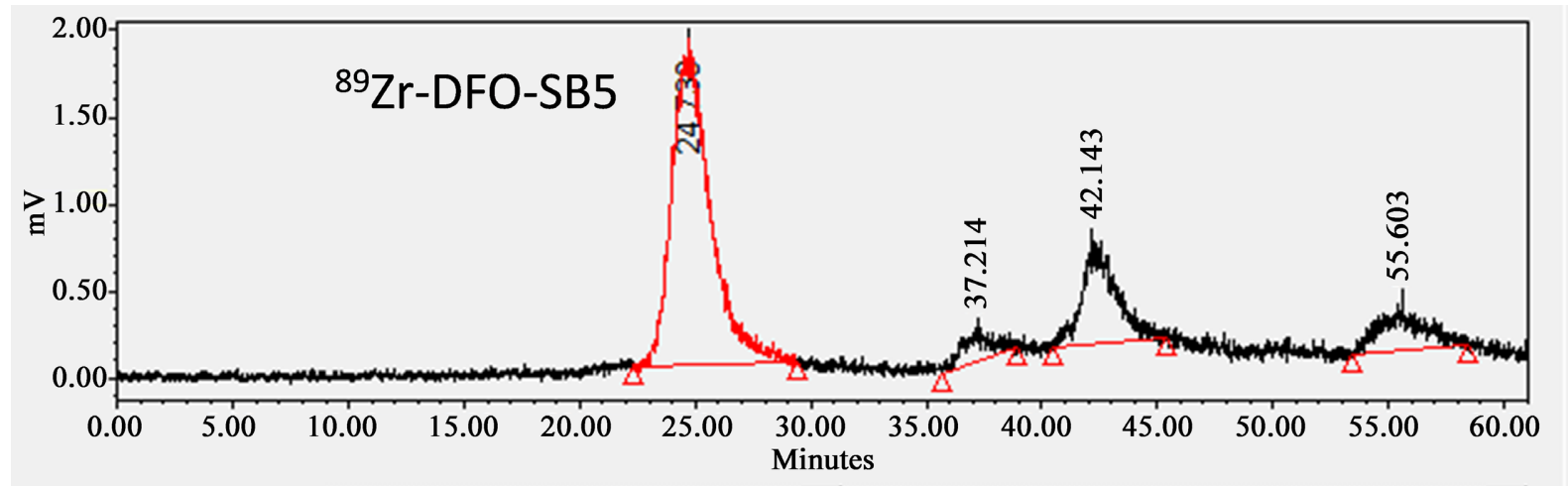

\begin{tabular}{|c|c|c|c|}
\hline $\begin{array}{c}\text { Retention Time } \\
(\mathrm{min})\end{array}$ & $\begin{array}{c}\text { Area } \\
\left(\mu \mathrm{V}^{2}\right)\end{array}$ & $\begin{array}{c}\text { Area } \\
(\%)\end{array}$ & $\begin{array}{c}\text { Height } \\
(\mu \mathrm{V})\end{array}$ \\
\hline 24.730 & 211,600 & 66.96 & 1861 \\
\hline 37.214 & 15,139 & 4.79 & 191 \\
\hline 42,143 & 57,615 & 18.23 & 602 \\
\hline 55.603 & 31,644 & 10.01 & 277 \\
\hline
\end{tabular}

Figure 2. Radiolabeling of DFO-SB5 conjugate. Radio-HPLC showed a peak of radiolabeled SB5 ([ $\left.{ }^{89} \mathrm{Z}\right]-\mathrm{DFO}-\mathrm{SB} 5$ ) as identified in (Figure 1).

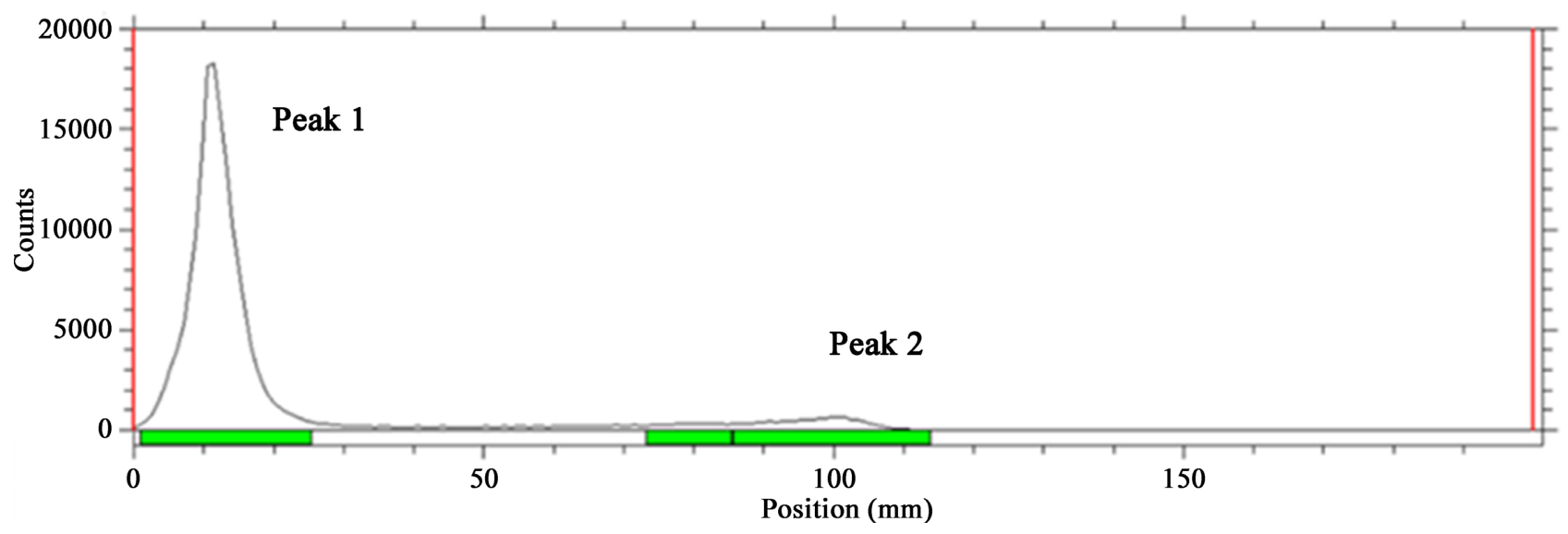

Figure 3. Radio-TLC of [ $\left.{ }^{89} \mathrm{Zr}\right]-\mathrm{DFO}-\mathrm{SB} 5$ showing quantitative radiolabeling yield. 

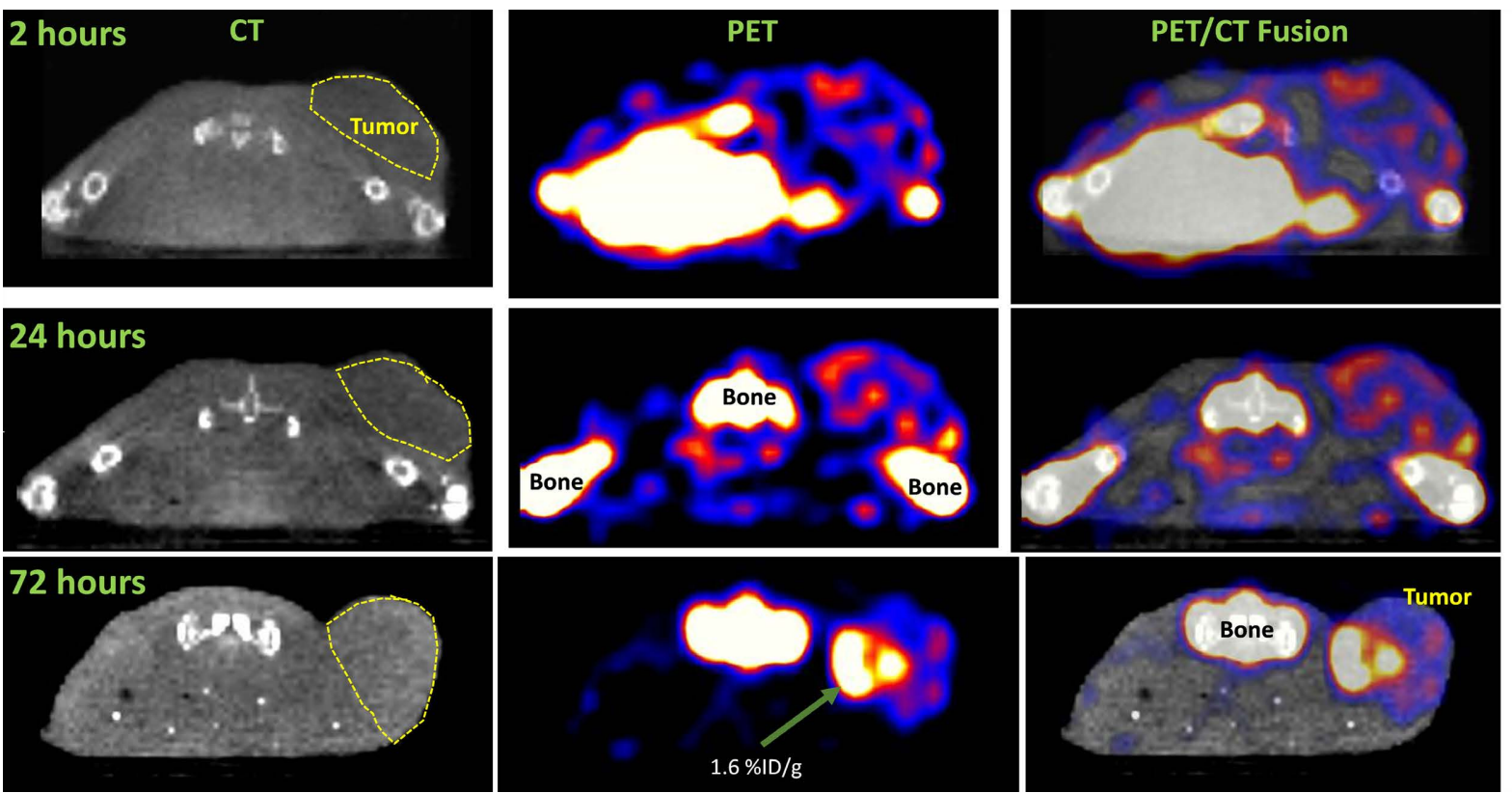

Figure 4. CT and PET images of mouse treated with ${ }^{89} \mathrm{Zr}$-radiolabeled SB5. Female nude mouse bearing xenograft tumor injected with $\left.{ }^{89} \mathrm{Zr}\right]-\mathrm{DFO}-\mathrm{SB} 5$ and imaged via PET/CT showed the Maximum Intensity Projection at 72 hours post-injection. Accumulation of ${ }^{89} \mathrm{Zr}$ ]-DFO-SB5 in the tumor and uptake in bone, liver, and spleen was observed.

from the blood, spleen, liver, and other organs. It is also observed that the right flank bearing tumor showed radioactive accumulation, whereas the left flank did not show any uptake. This confirms that the ${ }^{89} \mathrm{Zr}$-lablled SB5 antibody bound to its receptor, SAS1B. In addition, activity was also noticed in the bone, which is likely due to the detachment of ${ }^{89} \mathrm{Zr}$ from DFO and uptake by the bones

After 72 hours, biodistribution results showed that about $6 \%$ of radioactivity was in the blood whereas major of radioactivity was present in the liver, spleen, and kidney (Figure 6(a)). The non-specific antibody 3A4 (negative control antibody) also showed similar distribution with a low uptake (Figure 6(b)).

Data showed about $1 \%$ radioactivity of $\left[{ }^{89} \mathrm{Zr}\right]-\mathrm{DFO}-\mathrm{SB} 5$ was found in the tumor (Green bars), whereas non-specific uptake of radioactivity was present in blood, liver, and spleen. Excessive radioactivity in kidney showed clearance of the radioactivity. Non-specific labeled antibody $\left.{ }^{89} \mathrm{Zr}\right]-\mathrm{DFO}-3 \mathrm{~A} 4$ (blue) also showed distribution in other organs but to a lesser extent than that of $\left[{ }^{89} \mathrm{Zr}\right]-\mathrm{DFO}-\mathrm{SB} 5$. However, the uptake of $\left[{ }^{89} \mathrm{Zr}\right]-\mathrm{DFO}-3 \mathrm{~A} 4$ was lower than that of $\left.{ }^{89} \mathrm{Zr}\right]$-DFO-SB5.

\section{Discussion}

The PET/CT imaging is a non-invasive technique that can be used to gain knowledge for cancer progression, metastasis [25]. In this study, conjugation of anti-SAS1B (SB5) with the chelator DFO was performed before labeling with ${ }^{89} \mathrm{Zr}$ according to a published protocol [26]. The results showed greater than $90 \%$ conjugation yield of SB5 with DFO. HPLC with a size exclusion column was used to evaluate the cold conjugation yield. The conjugation solution of anti- SAS1B with 


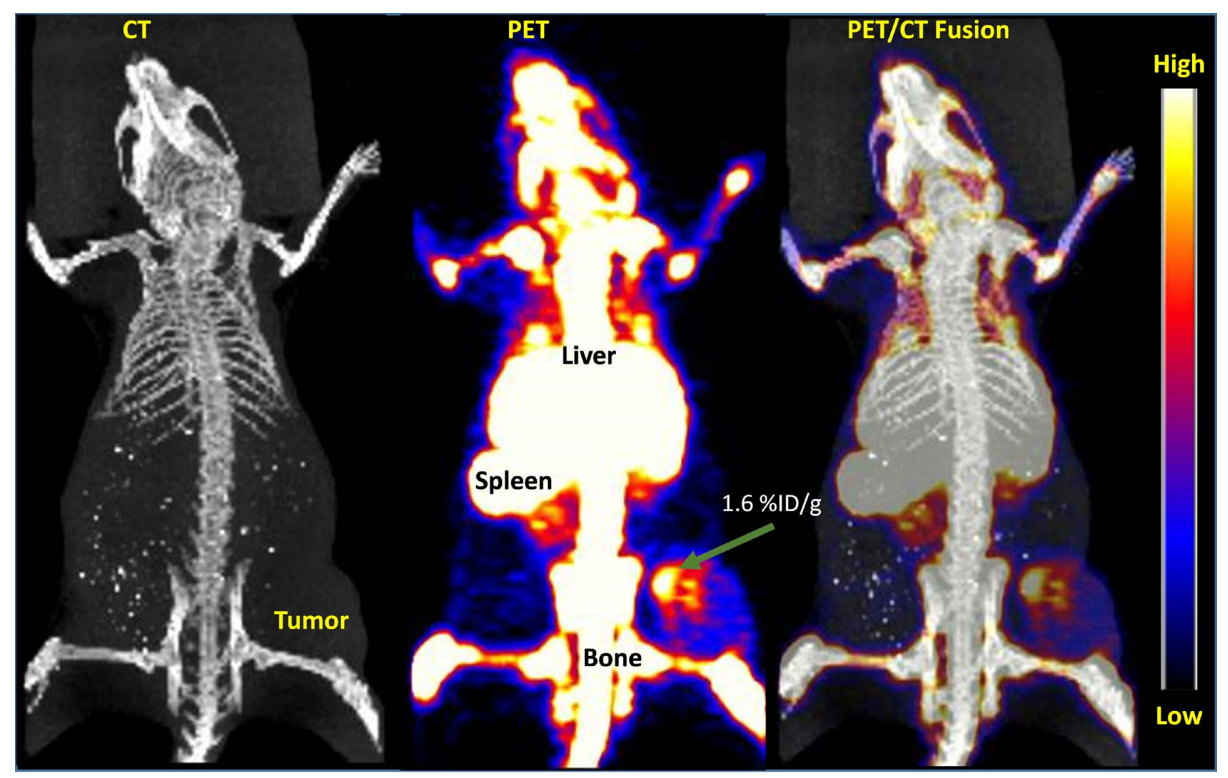

Maximum Intensity Projection 72 hours post injection

Figure 5. PET/CT coronal and sagittal images across tumor area. Images were taken at 2 hours, 24 hours, and 72 hours post-injection. Region of interest (ROI) results showed uptake of radioactivity in the tumor.

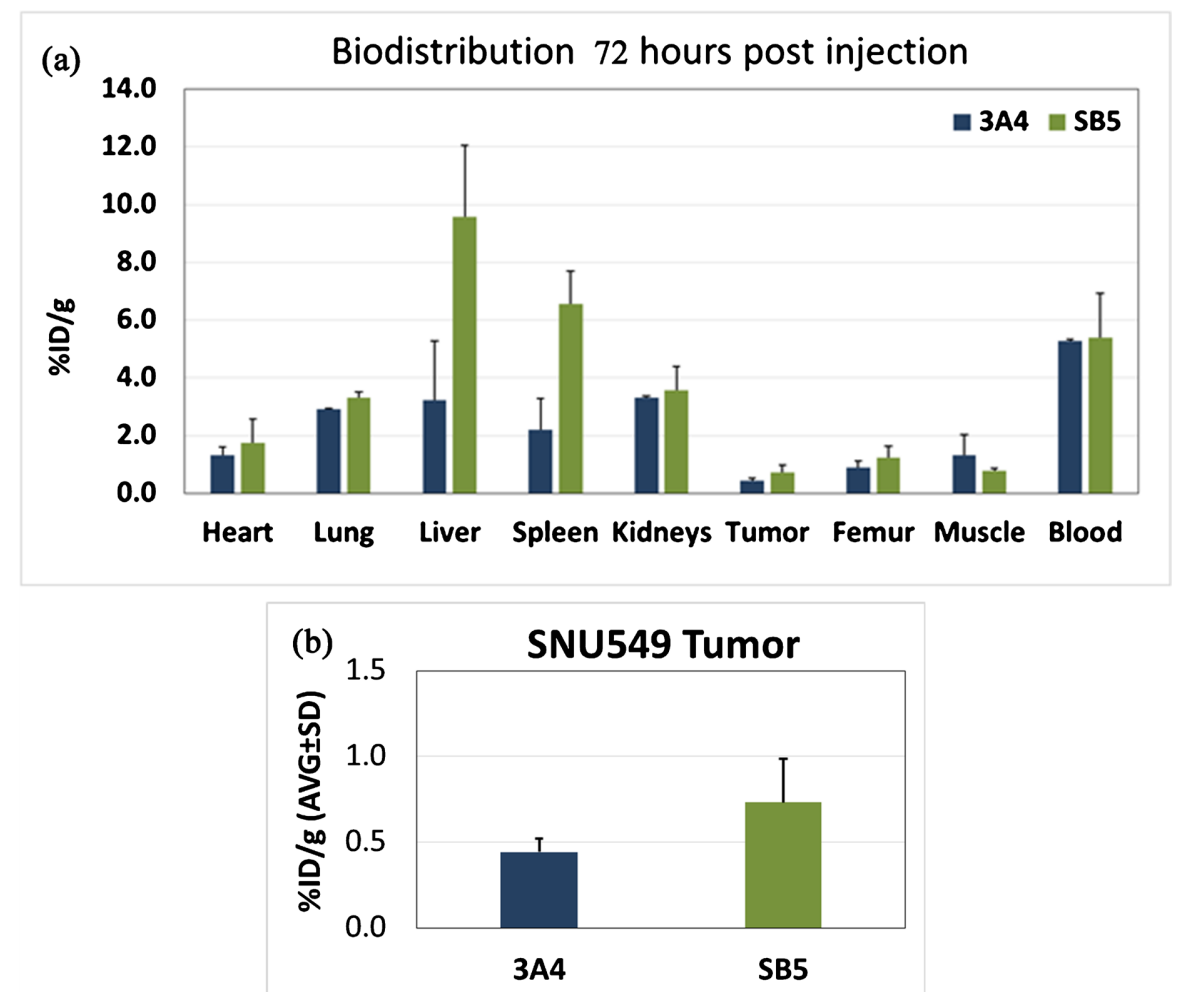

Figure 6. EX vivo results of $\left[{ }^{89} \mathrm{Zr}\right]-\mathrm{DFO}-\mathrm{SB} 5$ and $\left[{ }^{89} \mathrm{Zr}\right]-\mathrm{DFO}-3 \mathrm{~A} 4$ biodistribution. Mice were injected with radiolabeled antibodies ([ $\left.{ }^{89} \mathrm{Zr}\right]-\mathrm{DFO}-\mathrm{SB} 5$ or $\left.\left[{ }^{89} \mathrm{Zr}\right]-\mathrm{DFO}-3 \mathrm{~A} 4\right)$ and then scarified after 72 hours. The organs (a) and tumor tissues (b) were harvested and the radioactivity was measured using gamma-counting as described in the text above. The data is reported as radioactivity percent of injected dose per gram $(\% \mathrm{ID} / \mathrm{g})$. 
DFO separately was injected into the HPLC at the beginning of the reaction to identify the retention time of each one, based on their molecular weight. Since the antibody has a higher molecular weight than the chelator, the antibody retention time was 24 minutes, which is less than the retention time of the chelator DFO was at 37 minutes. When the cold conjugation was injected, the HPLC chromatograph showed two peaks. The area under the peaks represented the amount of antibody and the chelator in the conjugation reaction. Therefore, HPLC was used to quantitatively monitor the conjugation yield. The area under the peaks reflected the degree of conjugation efficiency.

Once reaction parameters are optimized and validated by radio-HPLC, a second chromatographic method, radio-TLC, was used to evaluate $\left[{ }^{89} \mathrm{Zr}\right]-\mathrm{DFO}-\mathrm{SB} 5$ labelling. This offers a quick and straightforward approach based on the migration of radiolabeled antibodies versus the migration of non-antibody radioactivity on the TLC plate. This method was adopted for rapid evaluation once being validated by radio-HPLC. This is done by scanning the entire plate using faster radiation detection. Labeled and the chromatograph showed about $80 \%$ of SB5 was labeled with ${ }^{89} \mathrm{Zr}$. Following the successful radiolabeling of SB5 with different yields, the radiolabeled antibodies were purified from non-antibody radioactivity. That resulted in a $97 \%$ yield (Figure 3 ).

We used CT and PET images to measure biodistribution. In general, $\mathrm{PET} / \mathrm{CT}$ images of $\left[{ }^{89} \mathrm{Zr}\right]-\mathrm{DFO}-\mathrm{SB} 5$ uptake reflect the biodistribution profile, including some uptake in tumors (Figure 5). The bone uptake is indicative of ${ }^{89} \mathrm{Zr}$ detaching from the radio-conjugate and accumulation in bone. This observation has been reported in other studies [27] [28] [29]. The overall biodistribution of $\left[{ }^{89} \mathrm{Zr}\right]-\mathrm{DFO}-\mathrm{SB} 5$ (specific for SAS1B) and $\left[{ }^{89} \mathrm{Zr}\right]-\mathrm{DFO}-3 \mathrm{~A} 4$ (presumed to be non-specific for SAS1B) is similar across several tissues, including blood. The SNU tumor uptake was slightly higher for $\left[{ }^{89} \mathrm{Zr}\right]-\mathrm{DFO}-\mathrm{SB} 5$ than for $\left[{ }^{89} \mathrm{Zr}\right]$-DFO-3A4, although the significance of this difference was not determined. It has been shown by western blot that SNU cells express more SAS1B antigen on their surface compared to 3A4-SAS1B expression level [11]. It is also worth noting that the uptake of $\left.{ }^{89} \mathrm{Zr}\right]-\mathrm{DFO}-3 \mathrm{~A} 4$ is $2-3$ times lower than that of $\left[{ }^{89} \mathrm{Zr}\right]-\mathrm{DFO}-\mathrm{SB} 5$ in both liver and spleen at 72 hours post-injection.

Eventually, a ligand that is both octadentate and oxygen-rich is believed to be the most stable $\mathrm{Zr}^{4+}$ chelator since it would be able to incorporate all eight coordination sites of zirconium [22]. In theory, this novel high stability $\mathrm{Zr}^{4+}$ ligand would minimize the uptake of liberated $\mathrm{Zr}^{4+}$ in the bone and other non-targeted tissues. To date, the design, synthesis, and evaluation of such a $\mathrm{Zr}^{4+}$ chelate require further research.

\section{Conclusion}

This is a preliminary study to conjugate ${ }^{89} \mathrm{Zr}$ radioactive tracer to anti-SAS1B. Our data showed limited success validating the conjugation and stability of tracer labelling with the antibody. However, it was of some concern that the radioac- 
tivity was also detected in other organs, this may be due to detachment of ${ }^{89} \mathrm{Zr}$ from the antibody. Further experiments are required to design more stable radioactive tracer labelling using other chelators such as HOPO [30] [31] [32].

\section{Conflicts of Interest}

The authors declare no conflicts of interest regarding the publication of this paper.

\section{References}

[1] Tian, M., He, X., Jin, C., He, X., Wu, S., Zhou, R., Zhang, X., Zhang, K., Gu, W., Wang, J. and Zhang, H. (2021) Transpathology: Molecular Imaging-Based Pathology. European Journal of Nuclear Medicine and Molecular Imaging, 48, 2338-2350. https://doi.org/10.1007/s00259-021-05234-1

[2] Wu, M. and Shu, J. (2018) Multimodal Molecular Imaging: Current Status and Future Directions. Contrast Media \& Molecular Imaging, 2018, Article ID: 1382183. https://doi.org/10.1155/2018/1382183

[3] Duclos, V., Iep, A., Gomez, L., Goldfarb, L. and Besson, F.L. (2021) PET Molecular Imaging: A Holistic Review of Current Practice and Emerging Perspectives for Diagnosis, Therapeutic Evaluation and Prognosis in Clinical Oncology. International Journal of Molecular Sciences, 22, 4159. https://doi.org/10.3390/ijms22084159

[4] Bernard-gauthier, V., Collier, T.L., Liang, S.H. and Vasdev, N. (2017) Imaging Technologies in Drug Discovery: Discovery of PET Radiopharmaceuticals at the Academia-Industry Interface. Drug Discovery Today. Technologies, 25, 19-26. https://doi.org/10.1016/j.ddtec.2017.09.001

[5] Vaquero, J.J. and Kinahan, P. (2015) Positron Emission Tomography: Current Challenges and Opportunities for Technological Advances in Clinical and Preclinical Imaging Systems. Annual Review of Biomedical Engineering, 17, 385-414. https://doi.org/10.1146/annurev-bioeng-071114-040723

[6] Kopka, K. (2014) Pharmaceuticals-Special Issue on Radiopharmaceutical Chemistry between Imaging and Endoradiotherapy. Pharmaceuticals, 7, 839-849. https://doi.org/10.3390/ph7070839

[7] Tsai, W.T.K. and Wu, A.M. (2018) Aligning Physics and Physiology: Engineering Antibodies for Radionuclide Delivery. Journal of Labelled Compounds and Radiopharmaceuticals, 61, 693-714. https://doi.org/10.1002/jlcr.3622

[8] Black, J.D., English, D.P., Roque, D.M. and Santin, A.D. (2014) Targeted Therapy in Uterine Serous Carcinoma: An Aggressive Variant of Endometrial Cancer. Women's Health, 10, 45-57. https://doi.org/10.2217/WHE.13.72

[9] Vitale, S., Laganà, A., Capriglione, S., Angioli, R., La Rosa, V., Lopez, S., Valenti, G., Sapia, F., Sarpietro, G., Butticè, S., Tuscano, C., Fanale, D., Tropea, A. and Rossetti, D. (2017) Target Therapies for Uterine Carcinosarcomas: Current Evidence and Future Perspectives. International Journal of Molecular Sciences, 18, 1100. https://doi.org/10.3390/ijms18051100

[10] Siegel, R.L., Miller, K.D. and Jemal, A. (2020) Cancer Statistics, 2020. CA: A Cancer Journal for Clinicians, 70, 7-30. https://doi.org/10.3322/caac.21590

[11] Pires, E.S., D’Souza, R.S., Needham, M.A., Herr, A.K., Jazaeri, A.A., Li, H., Stoler, M.H., Anderson-Knapp, K.L., Thomas, T., Mandal, A., Gougeon, A., Flickinger, C.J., Bruns, D.E., Pollok, B.A. and Herr, J.C. (2015) Membrane Associated Can- 
cer-Oocyte Neoantigen SAS1B/Ovastacin Is a Candidate Immunotherapeutic Target for Uterine Tumors. Oncotarget, 6, 30194-30211. https://doi.org/10.18632/oncotarget.4734

[12] Dammes, N. and Peer, D. (2020) Monoclonal Antibody-Based Molecular Imaging Strategies and Theranostic Opportunities. Theranostics, 10, 938-955.

https://doi.org/10.7150/thno.37443

[13] Weiner, G.J. (2015) Building Better Monoclonal Antibody-Based Therapeutics. Nature Reviews Cancer, 15, 361-370. https://doi.org/10.1038/nrc3930

[14] Nayak, T.K. and Brechbiel, M.W. (2009) Radioimmunoimaging with Longer-Lived Positron-Emitting Radionuclides: Potentials and Challenges. Bioconjugate Chemistry, 20, 825-841. https://doi.org/10.1021/bc800299f

[15] Akbar, G. (2020) Development and Modification in Therapeutic Antibodies to Combat Various Diseases. Pure and Applied Biology, 9, 2097-2110. https://doi.org/10.19045/bspab.2020.90224

[16] Dash, A. and Chakravarty, R. (2019) Radionuclide Generators: The Prospect of Availing PET Radiotracers to Meet Current Clinical Needs and Future Research Demands. American Journal of Nuclear Medicine and Molecular Imaging, 9, 30-66.

[17] Unterrainer, M., Eze, C., Ilhan, H., Marschner, S., Roengvoraphoj, O., Schmidt-Hegemann, N.S., Walter, F., Kunz, W.G., Rosenschöld, P.M.A., Jeraj, R., Albert, N.L., Grosu, A.L., Niyazi, M., Bartenstein, P. and Belka, C. (2020) Recent Advances of PET Imaging in Clinical Radiation Oncology. Radiation Oncology, 15, Article No. 88. https://doi.org/10.1186/s13014-020-01519-1

[18] Knowles, S.M. and Wu, A.M. (2012) Advances in Immuno-Positron Emission Tomography: Antibodies for Molecular Imaging in Oncology. Journal of Clinical Oncology, 30, 3884-3892. https://doi.org/10.1200/JCO.2012.42.4887

[19] McKnight, B.N. and Viola-Villegas, N.T. (2018) 89Zr-ImmunoPET Companion Diagnostics and Their Impact in Clinical Drug Development. Journal of Labelled Compounds and Radiopharmaceuticals, 61, 727-738. https://doi.org/10.1002/jlcr.3605

[20] Fischer, G., Seibold, U., Schirrmacher, R., Wängler, B. and Wängler, C. (2013) 89Zr, a Radiometal Nuclide with High Potential for Molecular Imaging with PET: Chemistry, Applications and Remaining Challenges. Molecules, 18, 6469-6490. https://doi.org/10.3390/molecules 18066469

[21] van de Watering, F.C.J., Rijpkema, M., Perk, L., Brinkmann, U., Oyen, W.J.G. and Boerman, O.C. (2014) Zirconium-89 Labeled Antibodies: A New Tool for Molecular Imaging in Cancer Patients. BioMed Research International, 2014, Article ID: 203601. https://doi.org/10.1155/2014/203601

[22] Deri, M.A., Zeglis, B.M., Francesconi, L.C. and Lewis, J.S. (2013) PET Imaging with 89Zr: From Radiochemistry to the Clinic. Nuclear Medicine and Biology, 40, 3-14. https://doi.org/10.1016/j.nucmedbio.2012.08.004

[23] Perk, L.R., Vosjan, M.J.W.D., Visser, G.W.M., Budde, M., Jurek, P., Kiefer, G.E. and van Dongen, G.A.M.S. (2009) p-Isothiocyanatobenzyl-desferrioxamine: A New Bifunctional Chelate for Facile Radiolabeling of Monoclonal Antibodies with Zirconium-89 for Immuno-PET Imaging. European Journal of Nuclear Medicine and Molecular Imaging, 37, 250-259. https://doi.org/10.1007/s00259-009-1263-1

[24] Dilworth, J.R. and Pascu, S.I. (2018) The Chemistry of PET Imaging with Zirconium-89. Chemical Society Reviews, 47, 2554-2571. https://doi.org/10.1039/C7CS00014F

[25] Hernández, D.L.D.G. (2015) The Role of PET/CT Imaging in Lung Cancer. Journal 
of Cancer Therapy, 6, 690-700. https://doi.org/10.4236/jct.2015.68076

[26] Vosjan, M.J.W.D., Perk, L.R., Visser, G.W.M., Budde, M., Jurek, P., Kiefer, G.E. and van Dongen, G.A.M.S. (2010) Conjugation and Radiolabeling of Monoclonal Antibodies with Zirconium-89 for PET Imaging Using the Bifunctional Chelate p-Isothiocyanatobenzyl-Desferrioxamine. Nature Protocols, 5, 739-743.

https://doi.org/10.1038/nprot.2010.13

[27] McDonagh, P.R., Sundaresan, G., Yang, L., Sun, M., Mikkelsen, R. and Zweit, J. (2018) Biodistribution and PET Imaging of 89-Zirconium Labeled Cerium Oxide Nanoparticles Synthesized with Several Surface Coatings. Nanomedicine: Nanotechnology, Biology and Medicine, 14, 1429-1440.

https://doi.org/10.1016/j.nano.2018.04.002

[28] Abou, D.S., Ku, T. and Smith-Jones, P.M. (2011) In Vivo Biodistribution and Accumulation of 89Zr in Mice. Nuclear Medicine and Biology, 38, 675-681.

https://doi.org/10.1016/j.nucmedbio.2010.12.011

[29] Raavé, R., Sandker, G., Adumeau, P., Jacobsen, C.B., Mangin, F., Meyer, M., Moreau, M., Bernhard, C., da Costa, L., Dubois, A., Goncalves, V., Gustafsson, M., Rijpkema, M., Boerman, O., Chambron, J.C., Heskamp, S. and Denat, F. (2019) Direct Comparison of the in Vitro and in Vivo Stability of DFO, $\mathrm{DFO}^{*}$ and DFOcyc$1 \mathrm{o}^{\star}$ for $89 \mathrm{Zr}$-immunoPET. European Journal of Nuclear Medicine and Molecular Imaging, 46, 1966-1977. https://doi.org/10.1007/s00259-019-04343-2

[30] Deri, M.A., Ponnala, S., Zeglis, B.M., Pohl, G., Dannenberg, J.J., Lewis, J.S. and Francesconi, L.C. (2014) Alternative Chelator for 89Zr Radiopharmaceuticals: Radiolabeling and Evaluation of 3,4,3-(LI-1,2-HOPO). Journal of Medicinal Chemistry, 57, 4849-4860. https://doi.org/10.1021/jm500389b

[31] Allott, L., da Pieve, C., Meyers, J., Spinks, T., Ciobota, D.M., Kramer-Marek, G. and Smith, G. (2017) Evaluation of DFO-HOPO as an Octadentate Chelator for Zirconium-89. Chemical Communications, 53, 8529-8532. https://doi.org/10.1039/C7CC03572A

[32] Carbo-Bague, I., Li, C., Gao, Y., Schreckenbach, G. and Ramogida, C. (2021) Synthesis and Radiolabeling of a Novel Decadentate Ligand 3,4,3,3-(LI-1,2-HOPO). Nuclear Medicine and Biology, 96-97, S12-S13. https://doi.org/10.1016/S0969-8051(21)00286-9 